\title{
Investigación literaria: postulaciones políticas en la novela colombiana del siglo XX
}

\author{
Literature research: political postulations in the twentieth century Colombian novel
}

\section{Resumen}

En este artículo se presentan los resultados de la investigación "Las postulaciones políticas presentes en la novela colombiana del siglo XX”, la cual inició en el primer semestre del 2009 con los estudiantes de quinto semestre de la Licenciatura en Educación Básica con énfasis en Humanidades, Lengua Castellana e Inglés de la Universidad

Cooperativa de Colombia, sede Bucaramanga. Esta investigación planteó un amplio

corpus en el que se seleccionaron algunas novelas representativas de la novela de la violencia en Colombia. En la novela colombiana se producen una serie de imaginarios que van quedando plasmados en las diferentes manifestaciones culturales, de las que hace parte la política de este país. Por ello, la investigación se dividió en dos conjuntos y en este artículo se entregan los resultados finales.

Palabras clave Novela, postulaciones políticas, violencia.

\begin{abstract}
This article presents the results of the research: The politics applications contained in the Colombian novel of the twentieth century. It started in the first semester of 2009 with V semester students of the Basic Education Degree with Emphasis in Humanities, Spanish language and English at the Universidad Cooperativa de Colombia in Bucaramanga. This research raised a large corpus in which some representative novels of the novel of violence in Colombia were selected. In the Colombian novel are imaginary series which are reflected in the different cultural manifestations, as the politics of this country. Therefore, the research was divided into two cohorts and in this article gives

the final results.
\end{abstract}

Keywords Novel, political postulations, violence.
Erika-Zulay Moreno-Bueno* Jairo Castro-Neira ${ }^{\text {*** }}$

Recibido: 4 de marzo del 2011 Aprobado: 18 de abril del 2011

Cómo citar este artículo: Moreno-Bueno Erika-Zulay y Castro-Neira, Jairo (2011), "Investigación literaria: postulaciones politicas en la novela colombiana del siglo XX", en Rastros Rostros, vol. 13, núm. 25, pp. 51-61.

Licenciada en Idiomas del la Universidad Industrial de Santander. Magíster en Semiótica de la Universidad Industrial de Santander. Docente de la Universidad Cooperativa de Colombia sede Bucaramanga. Investigadora del grupo "Pedagogía y Lenguajes". Correo electrónico: erika.moreno@campusucc.edu.co

** Licenciado en Idiomas de la Universidad Industrial de Santander. Magíster en Semiótica de la Universidad Industrial de Santander. Docente de la Universidad Cooperativa de Colombia, sede Bucaramanga. Investigador del grupo "Pedagogía y Lenguajes". Correo electrónico: jairo.castro@campusucc.edu.co 


\section{Introducción}

1 proyecto que se plantea a continuación tiene como objetivo identificar las postulaciones políticas presentes en la novela colombiana del siglo XX, en la cual se producen una serie de imaginarios que van quedando plasmados en las diferentes manifestaciones culturales, de la cual hace parte la política de este país.

Como bien lo señala Rafael Gutiérrez Girardot (1990), lo más interesante a analizar en la literatura hispanoamericana es la función histórica del propio escritor, quien desde el momento de la independencia política de estas naciones de América asumió su papel de mediador de un proceso intelectual que lo llevó a establecer, en nuestro medio social, una literatura moderna. El escritor debe enfrentarse a la tarea de introducir los nuevos idearios políticos de la modernidad, la razón como pauta de la vida política y social, la libertad de pensamiento, así como la serenidad y el gozo de las letras, por lo que ellas transmiten de saber y de duda. El escritor representa una minoría intelectual con una sensibilidad insólita, con una capacidad de reflexión desacostumbrada que indaga y desea estar en comunicación frecuente con los símbolos, que son más generales que las situaciones concretas inmediatas de la vida cotidiana.

Este papel mediador, difusionista y polémico, es una característica notable que se hace muy ostensible en los escritores colombianos, pues es en las letras en las cuales se encuentra el punto de partida del laboratorio de la política del país, de allí emerge signada por un sentido libertario, polémico, doctrinario y arisco quizás, haciendo eco en ese difusionismo que los intelectuales buscaron, tal como la autonomía del espíritu que marcara el tránsito de una sociedad teocrática a una civil, en la cual el funcionario religioso se sustituyó por el hombre de letras.

Es precisamente en esta perspectiva, en la relación literatura-política, como se enfrentó el análisis de la novela colombiana que se produce en el siglo XX. Para ello se consideró lo anteriormente planteado y además se realizó un estado del arte del corpus analizado, seguido a esto, se planteó un anteproyecto que dio pauta a la redacción de 14 monografías que contienen a su vez 14 propuestas pedagógicas del uso y la pertinencia de la literatura en el aula, dos seminarios regionales, la publicación de dos números de la revista Rastros Rostros y la participación en eventos fuera de la universidad.

Este proyecto se desarrolló en la Universidad Cooperativa de Colombia, sede Bucaramanga, con la participación activa de los estudiantes que actualmente cursan los semestres octavo y noveno de la Licenciatura en Educación Básica con énfasis en Humanidades, lengua castellana e inglés. La investigación comenzó en el primer semestre del 2009 y desde esa fecha hasta ahora, primer semestre del 2011, se han venido generando una serie de productos y resultados importantes tanto en la formación de estos futuros egresados como para el grupo de investigación Pedagogía y Lenguajes. Además de mencionar la satisfacción personal de todos los que intervinieron en este proceso.

Esta propuesta de lectura crítica y analítica de la novela colombiana del siglo XX contempla las siguientes obras y autores, los cuales se consignan aquí en un orden puramente cronológico:

1. El gran Burundú-Burundá ha muerto. Jorge Zalamea (1952).

2. El Cristo de espaldas. Eduardo Caballero (1952).

3. Viento seco. Daniel Caicedo (1954).

4. El coronel no tiene quien le escriba. Gabriel García Márquez (1957).

5. Cóndores no entierran todos los días. Gustavo Álvarez Gardeazabal (1971).

6. La casa de las dos palmas. Manuel Mejía Vallejo (1988).

7. Viva Cristo Rey. Silvia Galvis (1991).

8. Noticia de un secuestro. Gabriel García Márquez (1996).

9. La virgen de los sicarios. Fernando Vallejo (1998).

10. Rosario Tijeras. Jorge Franco (1999). 


\section{Metodología}

Como presupuesto básico del eje central de este proyecto de investigación se plantea la siguiente pregunta, ¿cuáles postulaciones políticas presentes en la novela colombiana del siglo XX tienen incidencia en la configuración del actual Estado Social de Derecho del país?, para dar respuesta a esta inquietud es necesario justificar el porqué de la realización de este proyecto.

Desde la consolidación de lo que hoy conocemos como República de Colombia, se da inicio a un proyecto político enmarcado dentro del ámbito de las ideas de la ilustración europea, trayendo de esta corriente tanto las costumbres sociales como las instituciones políticas. Fue desde los comienzos de la República en que los considerados intelectuales hispanoamericanos, visionarios políticos tendrían en sus manos la responsabilidad de iniciar el proceso de la consolidación del Estado.

La configuración de los Estados modernos hispanoamericanos tiene como herencia la tradición del pensamiento ilustrado, en su vertiente liberal (no entendido como el partido político, sino como ideario), cuyos planteamientos tendrán como pilares fundamentales: la formación de una conciencia de ciudadano y ciudadanía que sustituyen la idea de súbdito y dependiente político; la actividad económica individual como distribución de la riqueza; y la filosofía de la ilustración, base de la constitución del sujeto autónomo y libre, cuyo valor intrínseco se expresa a través de la idea de dignidad, es decir, la aparición del ciudadano democrático, la del homo oeconomicus y la del sujeto libre (Godoy Arcaya, 1991).

Es entonces, dentro de este contexto, y teniendo en cuenta que muchos de los hombres que juegan un papel fundamental en el proceso de pensar y construir país son quienes tienen vocación literaria, como se debe comprender el papel mediador que juega la literatura en la difusión o resistencia de las nuevas ideas.
La literatura como manifestación de las preocupaciones más profundas del alma humana ha sido la posibilidad de expresión en la que los hombres plasman sus ideales, sus dudas, sus deseos, sus resistencias, sus acuerdos o desacuerdos, a favor o en contra de los acontecimientos que rodean su existencia en un momento dado de su devenir histórico. A través de las letras, los hombres forjan su pensar y sentir frente a los acontecimientos esenciales que les son propios en el momento de su existencia o de su tránsito por el mundo. Corresponde entonces al campo de los estudios literarios reflexionar acerca de las huellas o rastros que dichas preocupaciones han dejado plasmadas en los textos literarios que se han producido en los diferentes momentos de su devenir histórico y en nuestro caso particular del devenir como Estado en el contexto de la modernidad política y social.

Cada autor narra su tiempo, sea para llamar la atención sobre la lucha partidista, guerrillera, paramilitar o de narcotráfico, que además muestra a lo largo del siglo XX el paso de un escenario rural a uno citadino. Entre tantas razones que pueden promover el estudio de este tema, es necesario nombrar las siguientes: la búsqueda, hallazgo y sustentación de las huellas políticas del Estado colombiano en la novela del siglo XX, entendido desde la necesidad de configurar a través de la historia la consolidación del Estado que constituye la base de la comprensión de la política actual colombiana, y las contradicciones de nuestra propia época a partir de los elementos dados en las novelas que serán objeto de análisis de este trabajo.

Además, la literatura juega un papel contestatario, como un arma latente que está allí para denunciar, pues, como lo señala Rafael Gutiérrez Girardot (1990), no se puede comprender una época sin las resistencias que frente a ella se hicieron o sin los contra-discursos que ella suscitó y provocó. Y finalmente, subyace a esta inquietud investigativa su relevancia en términos del compromiso académico

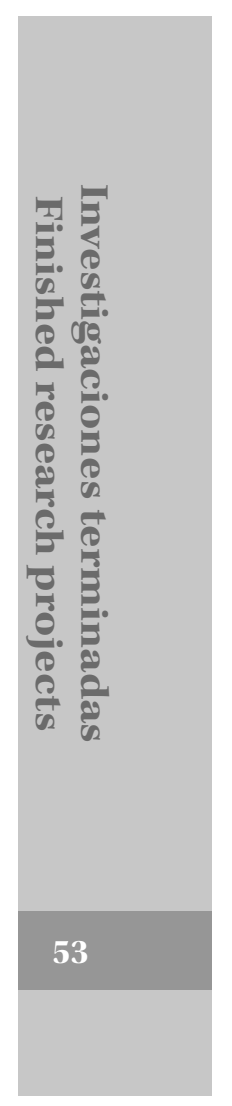

Revista Rastros Rostros - Volumen 13, Número 25 - enero-junio 2011 
y de su contribución a las investigaciones llevadas a cabo sobre el problema del Estado colombiano y de la identidad nacional, por cuanto contribuye a subsanar un vacío en el conocimiento.

Se debe considerar hoy el estudio de la poética, que, como bien lo dice Paul Ricoeur (2000), ha sido entendida como la disciplina que trata de las leyes de la composición que se añaden a la instancia discursiva para dar lugar a un texto, al que se considera un relato, un poema o un ensayo. Asimismo, la poética trata las estructuras profundas en las que se anclan cada una de las manifestaciones estéticas, preámbulo justo y necesario que permite desentrañar los imaginarios sociales, las construcciones simbólicas y los paradigmas axiológicos que están en la base de un entramado social y cultural, con el cual uno puede identificarse y del que se forma parte.

Lo anterior justifica la necesidad de un trabajo de investigación y reflexión en torno a la producción poética del devenir de la nación colombiana. Dicho trabajo estará enmarcado entonces en la necesidad de explicación, comprensión e interpretación de los procesos simbólicos e imaginarios de construcción de la nación colombiana, para lo cual es pertinente el estudio crítico de dicha producción en la medida en que es a través de ella y en ella, entre otras manifestaciones, que se han construido los relatos nacionales que configuran y se configuran como miembros de una comunidad particular, pero también que permiten el diálogo y participación en un universo de intelección que se vincula a la historia de la humanidad en su conjunto.

La aparición de dichas manifestaciones estéticas que convergen en la configuración de la novela colombiana del siglo XX es correlativa con la necesidad que tiene un grupo cualquiera de procurarse una imagen de sí mismo, de "representarse en el sentido teatral de la palabra, de ponerse en juego y en escena” (Ricoeur, 1986, p. 255). Es aquí donde relato e imaginación se encuentran, se ponen a prueba, porque es a partir de ese encuentro que empieza la construcción de una identidad nacional; identidad que, como lo plantea Francois-Xavier Guerra, "remite siempre a lo que un grupo considera ser y a lo que, por lo tanto, lo vuelve diferente a los demás" (1997, p. 102). Dicha identidad, en palabras de este autor, puede ser considerada en dos registros diferentes: el político (lo que define a una colectividad con estatuto político reconocido y que posea un territorio, instituciones y gobierno propio) y el registro cultural (en el que se comparten un conjunto de representaciones colectivas respecto de las relaciones del grupo con la tierra, la historia, la providencia, sus vecinos).

Ahora bien, cuando se habla de novela colombiana del siglo XX, esto implica no solamente que cada época cuenta con relatos diferentes y que le son propios, pues ellos dependen de los contextos en los que han surgido, sino también que al interior de cada época hay relatos diferentes y heterogéneos, y que por consiguiente cuando se habla de la producción hecha a lo largo de los siglos se está teniendo en cuenta esta diversidad.

Si esto es así, se estaría en la línea de reflexión planteada por Gerome Bruner (2005), cuando señala que una cultura no cabe nunca en un sólo relato, motivo por el cual existen en la cultura una proliferación de dichos relatos y en ellos se soportan, tanto los individuos, como las sociedades en el transcurso de su historia. Historia que no sería entonces otra cosa sino el cúmulo de relatos en los que se cuenta el trasegar de una sociedad y que, según los diferentes puntos de vista, momentos históricos, intereses, ideologías, se pueden referir a la misma historia, en sus diferentes versiones, que se confirman, que se legitiman, que se contradicen, que se oponen, que se niegan, que se silencian o que se hacen evidentes.

El relato, cualquiera que sea su forma -mítico, literario, fáctico, relato de justicia, entre otros-, consiste siempre en una dialéctica entre lo que se espera y lo que se produce efectivamente. Para que haya historia es necesario que un acontecimiento imprevisto 
suceda; de lo contrario, "no hay historia" y las historias son la moneda y el emblema de la cultura, en el sentido de que la cultura, en su aspecto figurado, modela y determina las expectativas propias del país que las produce (Bruner, 2005, p. 28).

El relato, incluso el de ficción, da forma a la experiencia humana confiriéndole una especie de derecho a la realidad. La ficción, en su configuración, parte de lo que es familiar para sobrepasarlo y conducirnos hacia el dominio de lo posible, de lo que podría ser, de lo que hubiera podido ser, de lo que quizás un día pueda llegar a ser, nos dice Bruner (2005, p. 26). En este sentido es necesario aclarar que la cultura no concierne únicamente a la norma: se interesa por la dialéctica entre lo que releva de la norma y lo que es humanamente posible, y es precisamente de ello que se ocupa el relato.

Así, la poética, en sus diferentes manifestaciones, no se ocupa solamente de las formas de representación de una sociedad en un momento determinado, sino más allá de éstas, de cómo dichas formas en su relación con los contextos y con la cultura dan forma al mundo, moldean los espíritus que buscan construir un sentido a dicho mundo. Sin embargo, es necesario reflexionar acerca de la capacidad de representar y de representarse que los individuos y las sociedades han desarrollado a lo largo de su historia. Dicha capacidad estaría directamente relacionada con las necesidades más profundas, es decir, ontológicas del ser, en la medida en que las representaciones, asumidas por el ser en cuanto son correlatos de su propia existencia, se convierten en reguladoras de la cultura, no porque ellas se impongan desde afuera, sino porque el hombre, desde sus orígenes, poseería una especie de predisposición a representar, a relatar su historia y a acercarse a través de ella a un saber esencial (Bruner, 2002, p. 46).

Esta predisposición estaría dada por la necesidad que tenemos de contar y contarnos la historia más adaptada a una situación determinada, de explicar y explicarnos por qué los planes propios o las propias expectativas han o no funcionado, por qué las esperanzas han podido o no concretarse. De esta manera, la poética en su más amplia acepción está relacionada con la necesidad humana de representar o representarse, de narrar o narrarse su propia historia o la de otros, de explicar, comprender e interpretar, a través de las diferentes manifestaciones estéticas, las razones de la existencia.

En este sentido, es pertinente pensar que las reglas que rigen toda manifestación poética están tan profundamente inscritas en nosotros que las formas surgen de unas necesidades esenciales y que cualquiera que sea su origen e intención, al asumirlas, se acercan a la vida porque de ella emanan y hacia ella se conducen.

Es en esta perspectiva que se aborda entonces este trabajo sobre la novela colombiana del siglo XX, entendida ésta como el cúmulo de relatos, en sus múltiples formas y manifestaciones, producidos a lo largo del siglo pasado, con el fin de dar testimonio y dejar huella de lo sentido, pensado y vivido en un momento dado, cuya trascendencia sobrepasa los límites de dicha temporalidad y permite hoy un diálogo con nosotros mismos, con nuestros antecesores y con aquellos que vivirán en un tiempo futuro.

La novela colombiana, en sus múltiples manifestaciones, contiene como eje de configuración la idea moderna del contrato social, el cual cambia el eje de relación del hombre con el mundo y con la trascendencia, para situarlo en una centralidad en la que el individuo se compromete con la sociedad a partir de unos derechos y deberes que le dan su autonomía y le permiten reconocerse en la autonomía del otro, de los otros.

En este sentido, las proposiciones de mundo que emergen de estos relatos nacionales son y seguirán siendo el resultado de las inquietudes, de los deseos, de las preocupaciones, de los encuentros y desencuentros entre lo ideal y la realidad en los procesos de construcción de la nación. Ideal y realidad son

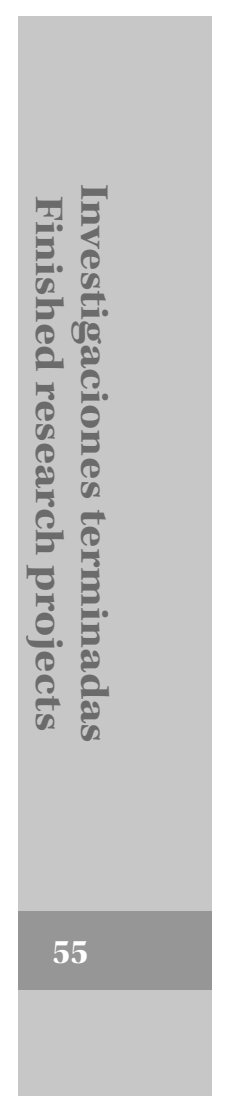

Revista Rastros Rostros - Volumen 13, Número 25 - enero-junio 2011 
construcciones, tanto individuales como colectivas en las que la configuración de las representaciones simbólicas juega un papel mediador y en las que es imprescindible tener en cuenta por los menos los tres niveles fundamentales para la explicación, comprensión e interpretación de dichas manifestaciones estéticas: el mundo real o prefigurado, el mundo de la obra o configurado y el mundo del lector o refigurado.

El acercamiento a cada uno de estos niveles reclama unos modos de aproximación que le son propios, para lo cual se acudirá a los aportes, tanto del análisis del discurso, de la sociocrítica y la de la hermenéutica textual, como de métodos de análisis de las diferentes manifestaciones poéticas que serán abordadas. Dentro de las perspectivas teóricas que apoyarán este estudio, se centra la atención en aquellas propuestas de análisis que permitan develar los valores fundamentales que se configuran en los textos objeto de esta reflexión, tal es el caso de propuestas como la de Paul Ricoeur (2004), Alfonso Cárdenas Páez (2004), entre otros.

En conclusión, se trata de una investigación de tipo cualitativo-interpretativo en la que la teoría del relato y el método de análisis sociocrítico permiten indagar en los diferentes niveles de significación de los textos literarios.

\section{Resultados}

Como se indicó anteriormente, esta investigación presentó dos momentos: el primero inició en el primer semestre del 2009 y se trabajaron las siguientes obras que corresponden al desarrollo de la temática desde un contexto rural:

1. El gran Burundú-Burundá ha muerto. Jorge Zalamea (1952).

2. El Cristo de espaldas. Eduardo Caballero (1952).

3. Viento seco. Daniel Caicedo (1954).

4. El coronel no tiene quien le escriba. Gabriel García Márquez (1957).
5. Cóndores no entierran todos los días. Gustavo Álvarez Gardeazábal (1971).

Se conformaron inicialmente cinco equipos de trabajo para abordar este corpus; sin embargo, y como una actividad fuera de lo planeado, se le entregó la obra La Cárcel (1972) de Jesús Zárate Moreno a un grupo de estudiantes que comenzaron la investigación en la última fase del mismo. Como producto del primer año de investigación se contó con el anteproyecto y la redacción del primer capítulo de la monografía, el cual corresponde a la prefiguración o el momento que desarrolla los espacios de experiencia del autor y su obra. Después, durante el segundo año de investigación, se obtuvo la redacción del segundo capítulo o la configuración, en la que los estudiantes realizaron un detallado análisis literario de sus obras. En este análisis se pueden encontrar todos los elementos que la componen como los sociolectos, los personajes, el tiempo, el narrador, entre otros. También se da la redacción del tercer y último capítulo de la monografía en el que se trabaja el mundo del lector o lo refigurado y a partir de allí surgen las siguientes propuestas pedagógicas que permiten llevar esta literatura al aula.

\section{Propuesta de El gran Burundún- Burundá ha muerto}

Mediante la lectura de la obra del autor colombiano Jorge Zalamea titulada El Gran Burundún-Burundá ha muerto, se pretende desarrollar la comprensión crítica y reflexiva en los estudiantes de noveno grado en torno a temas de gran interés como: dictadura, poder y violencia, además del uso constante de metáforas en nuestra sociedad actual. La inclusión de una obra literaria dentro del aula de clase es el principal material de apoyo para fomentar el análisis crítico de los estudiantes hacia la sociedad. Teniendo en cuenta lo anterior, lo que se desea lograr en los estudiantes es un aprendizaje significativo que conlleve al pensamiento crítico y reflexivo de la 
sociedad procurando en todo momento que sea el estudiante el que evalúe sus aprendizajes en pro de un beneficio cognitivo, en primera instancia, para luego hacerlos presentes en un saber hacer. Es por esto que se ha planteado como producto una obra de teatro con los estudiantes en la cual puedan representar la obra literaria El Gran BurundúnBurundá ha muerto frente a una audiencia, en este caso la comunidad educativa.

\section{Propuesta de El Cristo de Espaldas}

¿Cómo incentivar el gusto por la lectura en los estudiantes de séptimo grado por medio de la novela colombiana El Cristo de espaldas y demás actividades de lectura crítica como el cine foro? Actualmente los jóvenes se inclinan más por lo visual o perceptivo y por medio de un cine foro se puede lograr despertar el interés de ellos, para tomar la obra y leerla. Además de poder ver diferentes temáticas para lograr identificar con ayuda de los mismos estudiantes todas las características que posee la obra, también se les pueden entregar guías didácticas con las cuales ellos identificarán y le darán el curso a la obra, así ellos la representarán y se les quedará dicho aprendizaje en sus memorias para la vida.

\section{Propuesta de Viento Seco}

¿Cómo lograr que los estudiantes del grado noveno desarrollen su comprensión escrita critico-reflexiva, mediante la lectura de la obra Viento seco del escritor Daniel Caicedo? Con esta propuesta pedagógica se quiere logar un periódico escolar en el cual los estudiantes logren exponer y dar a conocer todos sus trabajos, además de esto, que logren reconocer la importancia que tiene la lectura en su vida, no sólo en el ámbito social, sino en todos los ámbitos. Es por esta razón que el estudio de esta obra se realiza de esta forma, ya que se da un espacio de interacción donde el estudiante pueda demostrar sus capacidades y a su vez ponerlas en práctica.

\section{Propuesta de El Coronel no tiene quien le escriba}

¿Cómo desarrollar la producción crítico-reflexiva mediante la lectura de la obra de Gabriel García Márquez, El coronel no tiene quien le escriba, en los estudiantes de octavo grado? El producto a lograr es que, a través de un teatro de títeres, los estudiantes se apropien de la novela pero actuándola, es decir, lo que se busca en este proyecto es darle a los estudiantes un rol de lectores que se apropian del guión para que puedan recibir la novela, y con esa experiencia de lectura y actuación tener una situación de más libertad, y por consiguiente de mayor responsabilidad a la hora de reproducirla desde su posibilidad crítico-reflexiva.

\section{Propuesta de Cóndores no entierran todos los días}

¿Cómo lograr que los estudiantes de décimo grado desarrollen su comprensión lectora y su producción crítica e interpretativa, mediante la lectura de Cóndores no entierran todos los días de Gustavo Álvarez Gardeazabal? A partir de lo propuesto se quiere lograr como producto final un ensayo en el cual quedará la producción crítica e interpretativa hecha por los estudiantes, esto como evidencia de la importancia y validez que tienen sus trabajos, de modo que se reconozca el esfuerzo de ellos y se pueda dar a conocer su trabajo mediante dicho ensayo que se crearía con el fin de manifestar, tanto a los estudiantes como a las personas que accedan a este material que los trabajos no se quedan sólo en un papel, que pueden servir de fuente y soportar próximas investigaciones o lecturas que incentiven a los estudiantes a crear buenos hábitos y que estimulen su desarrollo cognitivo, personal y social.

\section{Propuesta de La cárcel}

¿Cómo lograr que los estudiantes de noveno grado se acerquen a la literatura colombiana? La idea de esta propuesta es la de desarrollar talleres que

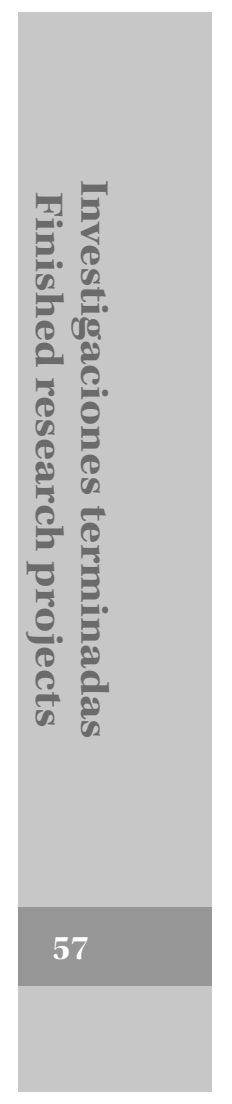

Revista Rastros Rostros - Volumen 13, Número 25 - enero-junio 2011 
incentiven a los estudiantes de noveno grado a leer obras de literatura colombiana del siglo XX, y para este fin se plantearon una serie de talleres de vinculación entre la caricatura y la historieta con la literatura colombiana.

El segundo momento se inició en el segundo semestre del 2009 trabajando cinco novelas que desarrollan su temática desde un contexto urbano:

1. La casa de las dos palmas. Manuel Mejía Vallejo (1988).

2. ¡Viva Cristo Rey!. Silvia Galvis (1991).

3. Noticia de un secuestro. Gabriel García Márquez (1996).

4. La virgen de los sicarios. Fernando Vallejo (1998).

5. Rosario Tijeras. Jorge Franco (1999).

Para realizar el proceso de investigación se conformaron ocho grupos de trabajo, los cuales realizaron el anteproyecto y el primer capítulo de la monografía, lo prefigurado, durante el primer año. Durante el segundo año se realizó el análisis literario de las obras, el cual abordó desde las categorías de personaje, espacio y tiempo, hasta las de narrador y pacto narrativo. El tercer capítulo, de lo refigurado, permite la construcción de las propuestas pedagógicas que a continuación se describen.

\section{Propuestas de La casa de las dos palmas}

\section{Primera propuesta}

Ante la necesidad de motivar a los estudiantes de noveno grado de básica secundaria a adquirir hábitos de lectura, se plantea como metodología de trabajo la representación de la obra a través de marionetas, las cuales son elaboradas con material de reciclaje, dado que desde la Universidad se hace énfasis en la protección del medio ambiente y el desarrollo sostenible (Universidad Cooperativa de Colombia, 2011, Visión).
Para tal fin, los alumnos se organizan en cinco grupos de trabajo, cada uno de los cuales se encarga del análisis y dramatización de cinco capítulos. Inicialmente, se hace un recuento general de la obra para que los estudiantes tengan una idea de cómo se realiza la trama, y a partir de ella se generan una serie de talleres sobre técnicas de comprensión lectora, construcción de argumentos y fabricación de las marionetas.

Esta aplicación de aprendizajes, de competencias para resolver problemas y toma de decisiones es aprovechada para generar conciencia ambiental (la misma que Mejía Vallejo identificar al destacar la imponencia del paisaje, las corrientes de agua, el verde de la montaña, seriamente afectado por el mal llamado desarrollo y ahora la globalización) en la representación de personajes y en la puesta en escena, mediante la cual los estudiantes pueden llegar a asimilar las realidades intelectuales, que sin ellos seguirían siendo exteriores y extrañas para su formación académica.

\section{Segunda propuesta}

Para llamar su atención y desarrollar las habilidades interpretativas y argumentativas de los estudiantes de noveno grado de los colegios públicos de Bucaramanga, se propone aplicar el proyecto de aula "Foro municipal de estudiantes del grado noveno pertenecientes a los colegios públicos de Bucaramanga”, en el cual se realizará la socialización de textos crítico-argumentativos basados en la novela La casa de las dos palmas.

En las ciencias sociales se debe fundamentar la búsqueda de alternativas a los problemas sociales que limitan la dignidad humana, para lo cual es importante forjar en niños y jóvenes posturas críticas y éticas, expresadas en textos críticosargumentativos partiendo de obras literarias, con base en la transversalización de las áreas de lengua castellana y ciencias sociales. 


\section{Propuestas de ¡Viva Cristo Rey?}

\section{Primera propuesta}

A partir de la lectura de la novela ;Viva Cristo Rey! de Silvia Galvis, se busca desarrollar la comprensión crítica de los estudiantes de décimo grado de los colegios públicos de Bucaramanga, promoviendo además la consulta bibliográfica sobre las temáticas que propone la novela, en las bibliotecas públicas de la ciudad, y para proponer el uso de Internet y los computadores como herramientas auxiliares de aprendizaje.

Se trata de sacar del aula de clases el análisis de la obra literaria para que el estudiante comprenda que el universo de la obra tiene relaciones directas con el mundo real y que temas como la violencia y la discriminación pertenecen a su mundo y pueden ser analizados y discutidos para proponer una sociedad más justa.

Los ensayos producidos por los estudiantes serán presentados por ellos en un seminario de socialización al que se invitarán expertos en temas sociales y críticos literarios.

\section{Segunda propuesta}

La propuesta pedagógica para desarrollar con los estudiantes de décimo grado de los colegios públicos de Bucaramanga pretende motivar la lectura de textos literarios a partir de la novela ;Viva Cristo Rey! de Silvia Galvis. La guerra civil es un tema de interés para recrear en una puesta en escena en la que se planteen además temas como la violencia, el amor, el sexo, la ambición y la injusticia social. Los talleres que se plantean centran su interés en los temas mencionados, y desarrollan habilidades escritoras para la producción de guiones y las habilidades actorales para la puesta en escena.

\section{Propuesta de Noticia de un secuestro}

El producto final de la propuesta pedagógica desarrollada a partir de la obra de Gabriel García Márquez
Noticia de un secuestro es una fotonovela en la que los estudiantes recrearán la obra. Los actores que darán vida a los personajes serán los mismos estudiantes y serán ellos también quienes diseñen el vestuario, ambienten las escenas y construyan los diálogos que aparezcan en los textos finales. Una entrega periódica por capítulos será presentada a la comunidad educativa de la institución.

\section{Propuesta de La virgen de los sicarios}

La propuesta de esta investigación abarca tres áreas de conocimiento: lengua castellana, sociales, y ética y valores. Tres áreas diferentes pero sintonizadas con el fin de que el estudiante se apropie de los diferentes aspectos de la historia colombiana del siglo $\mathrm{XX}$, a partir de la lectura de La virgen de los sicarios. El producto final será un reportaje literario e investigativo para el área de lengua castellana, una película producida y dramatizada por los mismos estudiantes para el área de sociales, y una revista de interés diverso adecuada a los temas de la novela para el área de ética y valores.

Que los estudiantes, a través de la lectura de la novela La virgen de los sicarios, logren conseguir un aprendizaje significativo y construir una imagen propia del mundo es la meta de este proyecto de aula. El acto de leer es como una transformación mental en la que el lector puede imaginar y recrear lo que la obra le presenta. Leer una novela, específicamente una novela colombiana, es estimular la mente hacia un pensamiento crítico. El estudiante logrará encontrarle el verdadero sentido a la lectura de la novela cuando la haga parte de su pasado, de su vida y cuando, por medio de actos escolares significativos como escribir reportajes periodísticos o realizar una película casera, se involucre como investigador o actor directo de las situaciones. Así logrará comprender que la historia colombiana necesita un cambio impetuoso, joven y apasionado.

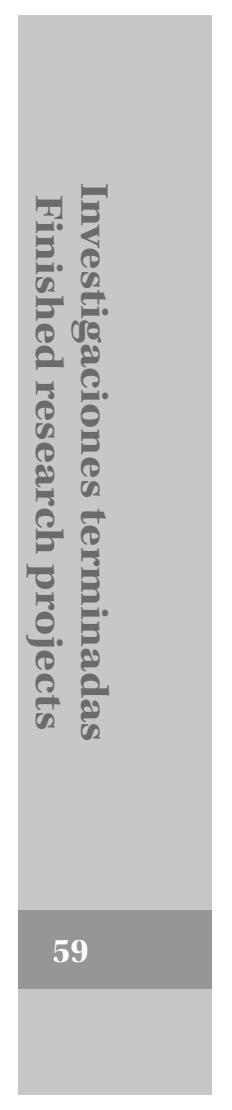

Revista Rastros Rostros - Volumen 13, Número 25 - enero-junio 2011 


\section{Propuestas de Rosario Tijeras}

\section{Primera propuesta}

El proyecto pedagógico de aula que se plantea pretende llevar de una manera didáctica la novela Rosario Tijeras a grupos del grado once de instituciones públicas y tiene como objetivo principal despertar el interés por la lectura de obras literarias en los estudiantes, para posteriormente lograr la lectura significativa de la novela de Jorge Franco, Rosario Tijeras. Lo que se pretende es la producción y puesta en escena de monólogos, para que la lectura de la novela resulte significativa. Durante los talleres en los que se realizarán numerosas y variadas actividades, los estudiantes trabajarán técnicas de escritura y de teatro, y finalmente representarán monólogos de los diferentes personajes de la obra.

\section{Segunda propuesta}

Se plantea un proyecto de aula para desarrollar con un grupo de décimo grado de un colegio público de Bucaramanga, con el objetivo de incentivar la lectura de textos literarios a partir de la novela Rosario Tijeras. La lectura y producción de textos argumentativos en los que se analizan diferentes problemas sociales de la Colombia de la última mitad del siglo XX formará parte de los talleres de aplicación de la propuesta.

\section{Conclusiones}

El trabajo investigativo desde Las postulaciones políticas de la novela colombiana del siglo XX fue un proceso de conocimiento de las bases políticas que motivaron las decisiones y el camino trazado en la historia de Colombia durante el siglo XX y que repercuten en la sociedad actual.

Los involucrados en la investigación obtuvieron diversos resultados personales y colectivos, así como la oportunidad de presentar los resultados de investigación en dos congresos regionales dentro de las instalaciones de la Universidad Cooperativa de Colombia, sede Bucaramanga; la presentación de sus disertaciones en un congreso internacional en la Universidad Nacional de Colombia; y cómo no mencionar la edición de dos números de la revista indexada Rastros Rostros.

Las propuestas pedagógicas desarrolladas en cada uno de los trabajos evidencian la necesidad que ven los maestros en formación de presentar la literatura en la escuela de una manera más lúdica y a la vez contextualizada con su propia realidad. En ellas se ve su afán por hacer de la lectura un acto de creación de mundos, de transformación del entorno; en ellas se adivina la idea de hacer de la lectura de obras literarias una oportunidad para desarrollar habilidades y para criticar la realidad, para formular propuestas y para transformar el mundo.

\section{Referencias}

Álvarez Gardeazábal, G. (1998), Cóndores no entierran todos los días, Bogotá, Panamericana.

Bruner, J. (2005), Pourquoi nous raconstons-nous des histoires?, Paris, Pocket.

Caballero, E. (1952), El Cristo de espaldas, Bogotá, Bolsilibros Bedout.

Caicedo, D. (1954), Viento seco, Bogotá, Universidad Nacional.

Franco Ramos, J. (1999), Rosario Tijeras, Madrid, Plaza \& Janés.

Galvis, S. (1991), ¡Viva Cristo Rey!, Bogotá, Planeta.

García Márquez, G. (1957), El coronel no tiene quien le escriba, Bogotá, Oveja negra.

García Márquez, G. (1996), Noticia de un secuestro, Bogotá, Norma.

Godoy Arcaya, O. (2000, julio-septiembre), Justicia política y justicia distributiva, Buenos Aires, Contribuciones.

Guerra, F. X. (1997), La nación en América hispánica, el problema de los orígenes, Buenos Aires, Nueva Visión. 
Gutiérrez Girardot, R. (1992), La formación del intelectual hispanoamericano en el siglo XIX, Maryland, University of Maryland at College Park.

Mejía Vallejo, M. (2003), La casa de las dos palmas, Bogotá, Nomos.

Ricoeur, P. (1986), Du texte à l'action, México DF, Siglo XXI.
Ricoeur, P. (2000), Narratividad, fenomenología y hermenéutica, México DF, Siglo XXI.

Ricoeur, P. (2004), Tiempo y narración, México DF, Siglo XXI.

Vallejo, F. (1994), La virgen de los sicarios, Madrid, Alfaguara.

Zalamea Borda, J. (1955), El gran Burundú-Burundá ha muerto, Buenos Aires, Nueva.

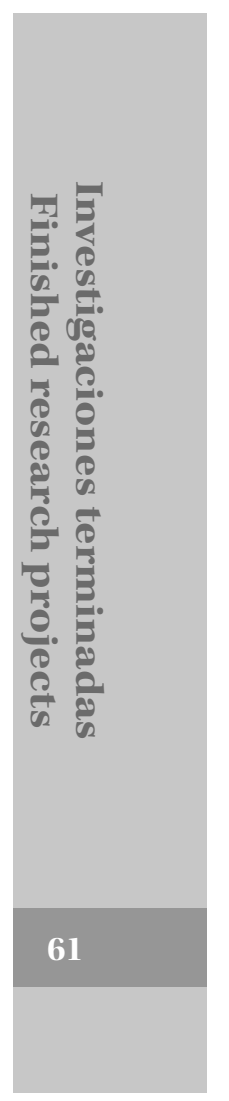

Revista Rastros Rostros - Volumen 13, Número 25 - enero-junio 2011 
